\title{
Habitat-Mediated Use of Space by Juvenile and Mating Adult Port Jackson Sharks, Heterodontus portusjacksoni, in Eastern Australia ${ }^{1}$
}

\author{
David Mark Powter ${ }^{2,3}$ and William Gladstone ${ }^{2}$
}

\begin{abstract}
Studies of spatial ecology of demersal sharks are critical to understanding the significance of habitat variation; however, limited information exists. Spatial ecology of adult Heterodontus portusjacksoni was studied at three locations on the central and southern coast of New South Wales, Australia, from January 2002 to December 2005. Juveniles within a nursery area were studied from December 2002 to December 2005. Tag-recapture, day and night underwater visual census, and acoustic tagging were used. Adults returned annually to the same coastal breeding reefs for up to four consecutive years. Individual juveniles resided within a sea-grass nursery area for at least $2 \mathrm{yr}$ and were not uniformly distributed throughout the nursery. Adult females often sheltered in aggregations in gutters as a male avoidance strategy, and both sexes utilized the sand/reef interface in the absence of gutters. Juveniles aggregated infrequently due to absence of habitat features that mediated aggregation. Acoustic tracks of adults revealed periods of inactivity up to $27 \mathrm{hr}$. Juveniles spent significant amounts of time inactive, punctuated with short bouts of swimming. Juveniles utilized moderate activity spaces $\left(3,510-583,990 \mathrm{~m}^{2}\right)$ centered over a core area of the sea-grass bed but also ranged over much larger areas of the bay. Use of space by $H$. portusjacksoni is strongly influenced by habitat characteristics throughout its life history.
\end{abstract}

The spatial ecology of fishes and elasmobranchs is defined by the extent of localized movements and more extensive migrations (Begon et al. 1990) and the use and magnitude of home ranges (Kramer and Chapman 1999), activity spaces (Simpfendorfer and Heupel 2004), site fidelity, philopatry, and natal homing (Hueter 1998). Temporal variations in movement patterns occurring over scales of days to seasons are also important

${ }^{1}$ This research was funded by grants from the University of Newcastle, Australian Geographic, and Project AWARE (PADI Asia-Pacific) and is a contribution from the Centre for Sustainable Use of Coasts and Catchments. Manuscript accepted 7 April 2008.

${ }^{2}$ School of Environmental and Life Sciences, University of Newcastle (Ourimbah Campus), P.O. Box 127, Ourimbah, New South Wales 2258, Australia.

${ }^{3}$ Corresponding author (e-mail: david.powter@ newcastle.edu.au).

Pacific Science (2009), vol. 63, no. 1:1-14

(C) 2009 by University of Hawai'i Press

All rights reserved
(Begon et al. 1990). However, an understanding of the spatial ecology of marine animals is limited compared with that of animals of the terrestrial environment (Klimley et al. 2001).

Home ranges have been documented for many elasmobranchs and refer to the area within which the majority, often $95 \%$, of an individual's localized movements and activities consistently occur (Seaman and Powell 1996). Although highly variable in size and shape, the advantage of maintaining a home range includes increased efficiency in the use of resources such as feeding sites, predator refuges, and breeding sites (Kramer and Chapman 1999). Home range size varies from $8.3 \mathrm{~km}^{2}$ in juvenile bonnethead sharks, Sphyrna tiburo (Heupel et al. 2006), to tens of thousands of square kilometers for adult lemon sharks, Negaprion brevirostris (Sundstrom et al. 2001). Site fidelity, or the tendency to preferentially return to the same restricted location after localized or migratory movements, is exhibited by many shark species (Heithaus 2001, Feldheim et al. 2002, Keeney et al. 2003). Although the reasons for 
this behavior remain unclear, it may relate to the reuse of quality habitat for purposes such as mating, feeding, or parturition (Hueter et al. 2004). Ontogenetic variation in spatial ecology is found in many sharks, with juveniles typically showing higher levels of site fidelity and more restricted activity spaces and repetitive movement regimes than adults (Heupel et al. 2004). Hence effective management and conservation require an understanding of this spatial ecology and its importance to the life history of individual shark species.

The spatial ecology of heterodontid sharks is incompletely known (Hueter et al. 2004). Species in this primitive elasmobranch order are largely benthic, and understanding their spatial ecology will expand understanding of the range of strategies used by sharks. Current knowledge of the diverse spatial ecology of sharks is based mostly on studies of nonbenthic species (Simpfendorfer and Heupel 2004). In particular, the spatial ecology of oviparous sharks is poorly understood. No definitive information exists about the home ranges or activity spaces of Heterodontus portusjacksoni (Meyer). Although they are known to occur within the same reef over short to medium terms (days to months), their diel movement patterns are known largely from pool studies, and limited quantitative evidence of site fidelity exists (McLaughlin and O'Gower 1971). Heterodontus portusjacksoni undertakes migrations away from the shallow, coastal breeding reefs each November to largely unknown locations and returns the following July (McLaughlin 1969). Although individuals have been observed to return to the same reef complex within a single breeding season (July to November), limited numbers are known to use the same breeding reef for more than one season. Juvenile $H$. portusjacksoni may live in nursery areas for several years (McLaughlin and O'Gower 1971), but nothing is known of their spatial ecology within these nurseries.

This study aimed to determine (1) patterns of site fidelity in adults' use of breeding reefs; (2) site fidelity of juveniles in a nursery area; (3) the dynamics of aggregative behavior; and (4) the activity spaces of adults and juveniles.

\section{MATERIALS AND METHODS}

\section{Study Sites}

Adult $H$. portusjacksoni were studied at Terrigal Haven $\left(33^{\circ} 26^{\prime} \mathrm{S}, 151^{\circ} 27^{\prime} \mathrm{E}\right)$, Cabbage Tree Harbour (33 $\left.16^{\circ} \mathrm{S}, 151^{\circ} 34^{\prime} \mathrm{E}\right)$, and Dent Rock, Jervis Bay $\left(35^{\circ} 04^{\prime} \mathrm{S}, 150^{\circ} 41^{\prime}\right.$ E), in New South Wales (NSW), Australia (Figure 1). These sites were shallow ( $<13 \mathrm{~m}$ deep) coastal rocky reefs with adjacent sand flats; Cabbage Tree Harbour and Dent Rock also possessed several gutters (narrow crevices with elevated sides and a depressed central channel occurring in the rocky substrate or formed by boulders). Juvenile $H$. portusjacksoni were studied in a shallow sea-grass nursery area at Murray's Sandline, Jervis Bay $\left(35^{\circ}\right.$ $08^{\prime} \mathrm{S}, 150^{\circ} 46^{\prime} \mathrm{E}$ ) (Figure 1). The sea-grass bed consisted of two contiguous regions of $750 \mathrm{~m}$, each of which was divided into three equal zones. The eastern region was closest to the bay's entrance and ranged in depth from 4.2 to $11.4 \mathrm{~m}$ (east to west), and the

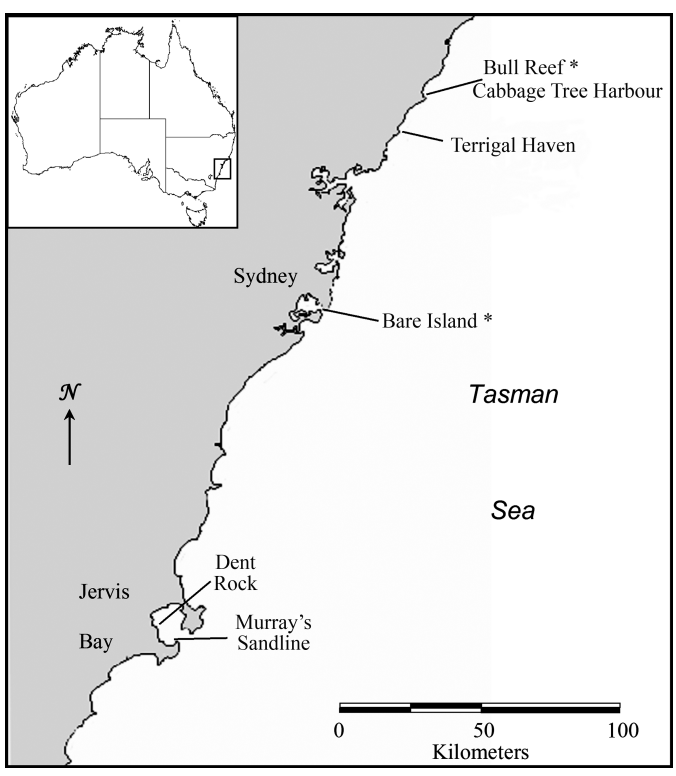

Figure 1. Map of the central and southern coast of New South Wales, Australia, showing location of the study sites. Inset shows the section of the eastern Australian coast depicted on the map. * indicates additional sites where sharks were tagged. 
western region reached a depth of $6 \mathrm{~m}$ at its western end. Murray's Sandline falls within the marine extension of the Booderee $\mathrm{Na}$ tional Park, which is continuous with the waters of the Jervis Bay Marine Park.

\section{Visual Surveys and Tagging}

Underwater visual census (UVC) surveys were conducted over fixed portions of the reef at each site. Terrigal Haven was surveyed twice weekly (1 day and 1 night) during the austral-winter onshore breeding season from July to November ( $n=131$ surveys) (hereafter called "the season") and at least monthly outside the season $(n=45)$. Cabbage Tree Harbour was surveyed four times per month (2 days and 2 nights) during the season $(n=57)$ and monthly outside the season $(n=15)$. Dent Rock $(n=29)$ and Murray's Sandline $(n=29)$ were surveyed monthly during daylight hours. Surveys commenced at Terrigal Haven in January 2002, at Cabbage Tree Harbour in July 2002, and at Dent Rock and Murray's Sandline in December 2002, and concluded at the four sites in December 2005. Despite differences in UVC frequency at adult sites, surveys were conducted across several years, during the entire breeding season, at different times of day, and across a range of weather conditions to ensure that observations were representative.

During surveys all $H$. portusjacksoni were, where possible, captured by hand, sexed (according to the presence/absence of claspers), and fitted with uniquely numbered Lazatags (Allflex, Brisbane, Australia) (adults) or double T-bar anchor tags (Hallprint, Victor Harbour, Australia) (juveniles) in the first dorsal fin before release. Total length (TL) measurements were recorded in situ using a tape measure as the distance between the snout tip and the tip of the upper caudal lobe. Any previously tagged sharks sighted during surveys were recaptured, sexed, measured, and released. Information concerning the tagging program was supplied to diving, angling, and commercial fishing groups and adult tags included contact details to encourage reporting of tag sightings.

\section{Site Fidelity}

Records of individually tagged adult and juvenile sharks from the UVC were used to determine the degree of site fidelity, with the site of resighted individuals compared with the original tagging site. The null hypothesis of no significant difference in the number of previously tagged male and female individuals that were resighted or resight occasions was tested overall and by site using $G$-tests (Sokal and Rohlf 1995). Every 3 months from August 2003 to December $2005(n=10)$, three timed UVC surveys were conducted in both regions (east, west) of the juvenile nursery. On each occasion the same observer swam at a constant rate for $10 \mathrm{~min}$ approximately $1-2$ $\mathrm{m}$ above the substrate while recording the number of juveniles observed (however juveniles could not be sexed at that distance). Replicate surveys were separated by a $1 \mathrm{~min}$ swim at the same rate. The null hypothesis of no significant difference in the number of juveniles surveyed in each of the $10 \mathrm{~min}$ survey zones and each region was tested using $G$-tests to assess site fidelity.

\section{Spatial Distribution and Aggregations}

During all surveys, the location of resting $H$. portusjacksoni individuals in relation to other individuals was noted. Individuals were considered to be aggregated if two or more occupied the same habitat feature (e.g., a gutter) or were within the divers' visual range (minimum $6 \mathrm{~m}$ ) of each other. The distance between all individuals was visually estimated to the nearest $10 \mathrm{~cm}$, and their sex was recorded. Visual estimates of distances were considered accurate due to the authors' experience in estimating sizes and distances underwater. Aggregation classes were defined as female-only, male-only, and mixed-sex. The null hypothesis of no significant difference in the number of individuals that were solitary or in aggregations was tested overall and by sex, site, or diel period using $G$-tests. The null hypothesis of no significant difference in the mean separation distance of individuals within each aggregation class was tested using $t$-tests. 


\section{Acoustic Telemetry}

Acoustic telemetry was utilized to determine activity spaces and to supplement observations of diel activity levels in adult and juvenile $H$. portusjacksoni. Individuals were fitted with a continuous acoustic pinger $(\mathrm{V} 13-1 \mathrm{H}$, Vemco, Halifax, Nova Scotia, Canada) attached to a normal dorsal tag by corrosible wire (juveniles) or galvanic couple (adults). Two male juveniles (N353, $290 \mathrm{~mm}$ TL; N354, 295 mm TL) were tracked at Murray's Sandline from 31 March to 2 April 2005. They were captured by hand and returned to a seawater holding tank aboard a waiting boat and fitted with an acoustic tag. After tagging, the juveniles were returned to their site of capture and released underwater by a diver, who subsequently observed the sharks to ensure that their behavior was normal after release. One adult male (J127, 1,111 mm TL) and one adult female (J126, 1,309 mm TL) were tracked at Dent Rock (Jervis Bay) from 12 to 13 October 2005. They were captured by hand underwater, fitted with an acoustic tag, released at the site of capture, and observed to ensure that behavior normalized after release.

The sharks were then tracked from a $4.5 \mathrm{~m}$ aluminum runabout using an acoustic receiver (VR60), omnidirectional hydrophone (VH65), directional hydrophone (VH10) (Vemco, Halifax, Nova Scotia, Canada), and a differential global positioning system (GPS) (Holland et al. 1992). The boat was regularly repositioned using signal strength readings from the directional hydrophone, with the boat's position assumed to be the position of the shark (Rechisky and Wetherbee 2003). The range and signal strength of the transmitter varies with depth, substrate type, substrate complexity, and ambient noise, but field tests revealed that the boat remained within $70 \mathrm{~m}$ of the transmitter at all times. An exact GPS location was recorded every 10 min. Tracking was conducted over a 48 hr period; however, the adult track was terminated after $27 \mathrm{hr}$ due to adverse weather conditions.

Manually recorded positions were plotted using ArcView 3.2 (ESRI, Inc., USA) Geo- graphic Information System software. The activity space of individual sharks was calculated in two ways using the HRE: The Home Range Extension for ArcView (Rodgers and Carr 1998), with periods during which individuals were unable to be located excluded from subsequent analyses. The minimum convex polygon method was utilized to determine the extent of an individual's range, and the $50 \%$ and $95 \%$ fixed kernel method was used to show the utilization of the activity space. The $50 \%$ and $95 \%$ kernels are considered activity spaces rather than home ranges due to the short temporal duration of this study (Rechisky and Wetherbee 2003). The null hypotheses of no significant difference in the number or duration of periods of activity and inactivity between day (0600 to 1800 hours) and night (1800 to 0600 hours) were tested using $G$-tests. Rate of movement was calculated using three or more consecutive points in a straight line and dividing the distance traveled by the time between position fixes (Cartamil et al. 2003).

\section{RESULTS}

\section{Site Fidelity}

Sixty-eight $(27.1 \%)$ of the 251 tagged adult $H$. portusjacksoni (all sites combined) were resighted at their original tagging site on a total of 137 occasions. Overall there was no significant difference in the total number of male and female individuals resighted $(G=0.94$, $\mathrm{df}=1, P=.33$ ). However females were resighted on significantly more occasions than males $(G=9.04$, $\mathrm{df}=1, P=.002)$. This pattern was not seen at Terrigal Haven, where there was no significant difference between the sexes in the number of individuals resighted $(G=0.67, \mathrm{df}=1, P=.41)$ or resighting occasions $(G=1.0, \mathrm{df}=1, P=.32)$. At Dent Rock there was no significant difference in the number of individuals of each sex resighted $(G=2.32, \mathrm{df}=1, P=.12)$, but females were resighted on significantly more occasions $(G=8.06, \mathrm{df}=1, P=.005)$.

The majority of resighted adult $H$. portusjacksoni were seen at the original tagging site. At Terrigal Haven and Dent Rock, these re- 
TABLE 1

Tag and Resighting Details for Adult and Juvenile H. portusjacksoni

\begin{tabular}{|c|c|c|c|c|c|}
\hline \multirow[b]{2}{*}{ Tag } & \multirow[b]{2}{*}{ Sex } & \multirow[b]{2}{*}{$\mathrm{TL}(\mathrm{mm})$} & \multirow[b]{2}{*}{ Tagging Site } & \multicolumn{2}{|c|}{ Resight } \\
\hline & & & & Days at Liberty & $\begin{array}{l}\text { Distance from } \\
\text { Tag Site }(\mathrm{km})\end{array}$ \\
\hline \multicolumn{6}{|l|}{ Adults } \\
\hline $\mathrm{C} 15$ & M & 975 & Bull Reef & 1,107 & 24 \\
\hline $\mathrm{C} 29$ & M & 927 & Terrigal Haven & 367 & 2.5 \\
\hline $\mathrm{C} 53$ & $\mathrm{~F}$ & 1,182 & Cabbage Tree Harbour & 393 & 11 \\
\hline C64 & $\mathrm{F}$ & 1,005 & Bull Reef & 393 & 24 \\
\hline $\mathrm{C} 97$ & M & 950 & Cabbage Tree Harbour & 699 & 4 \\
\hline $\mathrm{J} 40$ & $\mathrm{~F}$ & 900 & Jervis Bay & 1,090 & 11 \\
\hline J49 & $\mathrm{F}$ & 1,250 & Jervis Bay & 655 & 11 \\
\hline $\mathrm{J} 57$ & $\mathrm{~F}$ & 1,207 & Dent Rock & 731 & 11 \\
\hline \multicolumn{6}{|l|}{ Juveniles } \\
\hline N023 & $\mathrm{F}$ & 265 & Murray's Sandline & 102 & 2 \\
\hline N070 & $\mathrm{F}$ & 287 & Murray's Sandline & 3 & 2 \\
\hline N353 & M & 290 & Murray's Sandline & 28 & 2.5 \\
\hline $\mathrm{N} 354$ & $M$ & 295 & Murray's Sandline & 28 & 2.5 \\
\hline
\end{tabular}

sightings accounted for $94.0 \%$ and $98.5 \%$ of the total, respectively. No tagged individuals were resighted at Cabbage Tree Harbour; however, two individuals were resighted at nearby sites (Table 1). Only $3.6 \%$ of all resightings occurred remote from the tagging site $(>250 \mathrm{~km})$. A further $6.6 \%$ were resighted at nearby sites $(\leq 24 \mathrm{~km})$ (Table 1$)$.

The number of individual adults resighted at Terrigal Haven during the season in which they were tagged was similar to the number seen the following season (Table 2). Although the number of resightings decreased in subsequent years, individuals were resighted up to three seasons after tagging. A 1,060 $\mathrm{mm}$ TL female tagged at Terrigal Haven in 2002 (C02) was resighted there in each of the next three seasons. At Dent Rock, similar numbers of individuals were resighted in the same tagging season as in the next two seasons (Table 2). Individuals at Dent Rock were also resighted up to three seasons after tagging. Although no tagged individuals at Dent Rock were resighted there across all seasons, a 1,166 mm TL female tagged in 2003 (J104) was resighted in 2004 and 2005,

TABLE 2

Temporal Spread of Resightings of Tagged Adult H. portusjacksoni at the Original Tagging Site for Terrigal Haven and Dent Rock

\begin{tabular}{llcccc}
\hline \hline \multirow{2}{*}{ Site } & & \multicolumn{3}{c}{ Time between Tagging and Resightings $^{a}$} \\
\cline { 3 - 6 } & Sex & $<1$ season & +1 season & +2 seasons & +3 seasons \\
\hline \multirow{2}{*}{ Terrigal Haven } & Female & 8 & 6 & 4 & 3 \\
& Male & 7 & 8 & 1 & 1 \\
\multirow{3}{*}{ Dent Rock } & Total & 15 & 14 & 5 & 4 \\
& Female & 12 & 11 & 10 & 5 \\
& Male & 9 & 5 & 12 & 0 \\
& Total & 21 & 16 & & 5 \\
\hline
\end{tabular}

$a<1$ season: individuals resighted within the same season they were tagged; +1 season: individuals resighted in the following season; +2 seasons: individuals resighted two seasons after tagging; +3 seasons: individuals resighted three seasons after tagging. 


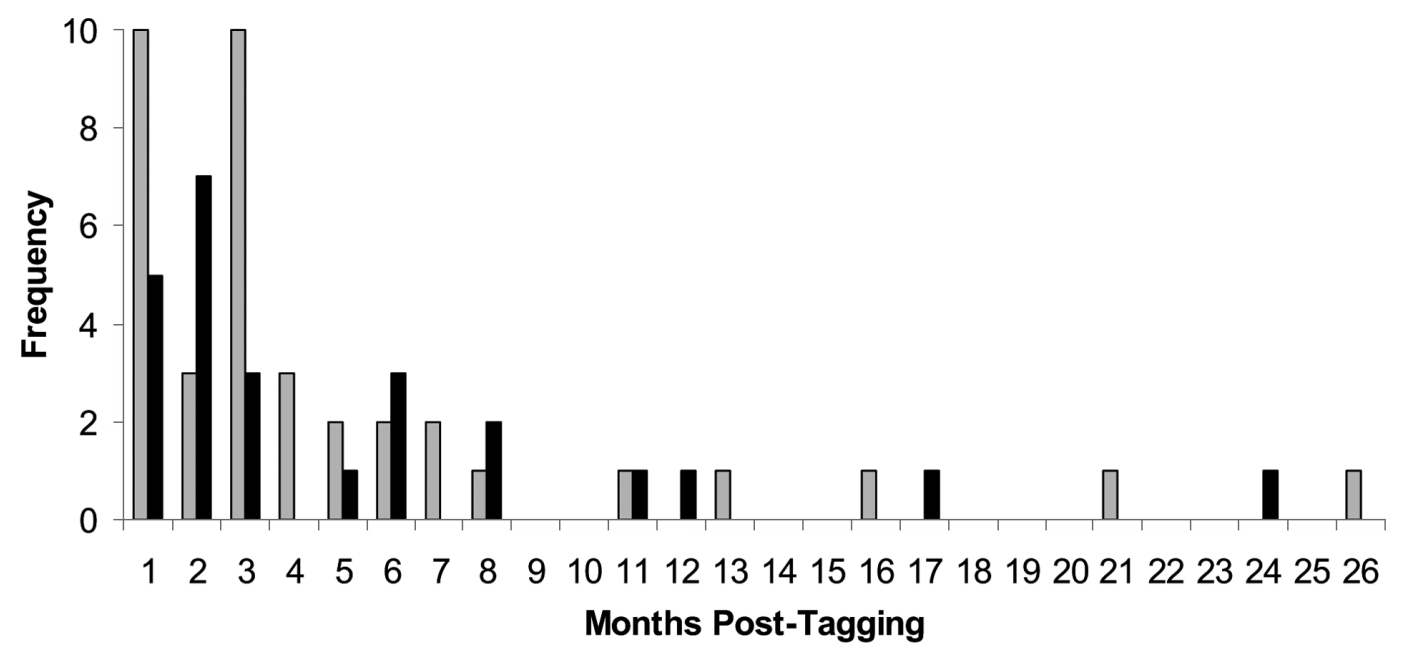

Figure 2. Temporal spread of tagged female (gray bars) and male (black bars) juvenile H. portusjacksoni resighted from 2001 to 2005.

and a 1,140 mm TL female (J52) tagged in 2002 was resighted in 2003 and 2004.

Fifty-one $(16.2 \%)$ of the 314 juveniles tagged at the nursery area were resighted on a total of 63 occasions. Most juveniles were resighted within 3 months of tagging, but individuals were resighted up to 26 months after tagging (Figure 2). There was no significant difference between sexes in the number of individuals resighted $(G=3.35, \mathrm{df}=1$, $P=.07)$ or in the number of resightings $(G=2.70, \mathrm{df}=1, P=.10)$. The vast majority $(92.2 \%)$ of all resightings occurred within the sea-grass bed where they were originally tagged. No juveniles were resighted at any sites remote from the tagging site, and only four juveniles (two male and two female) were resighted at a nearby reef $(\sim 2 \mathrm{~km}$ away) separate from the sea-grass bed (Table 1).

Significantly more juveniles occurred in the eastern region of the sea-grass bed $(n=$ 245) than in the western region $(n=55$; $G=130.04, \mathrm{df}=1, P<.001)$. Numbers of juveniles did not differ among the three zones of the eastern region. However, significantly more individuals occurred in western zone $1(n=33)$ than in western zone $2(n=12$; $G=10.19, \mathrm{df}=1, P<.001)$ or zone $3(n=$
$10 ; G=12.97, \mathrm{df}=1, P<.001)$. There was no significant difference between western zones 2 and 3.

\section{Spatial Distribution and Aggregations}

At Cabbage Tree Harbour significantly more adult females occurred in aggregations (73.6\%; $G=16.71, \mathrm{df}=1, P<.001)$ than were solitary; however there was no significant difference for males $(G=0.20$, $\mathrm{df}=1$, $P=.65)$, with $40.0 \%$ being solitary. The largest aggregation was 13 females and one male. Mixed aggregations consisted of more than one female and a single male. At Dent Rock, there was no significant difference in the number of solitary or aggregating sharks by sex, with $50.9 \%$ of females $(G=0.06$, $\mathrm{df}=1, P=.81)$ and $53.6 \%$ of males $(G=$ $0.29, \mathrm{df}=1, P=.59)$ occurring in aggregations. The largest aggregations consisted of eight individuals - one of eight males and another of two females and six males. Male-only aggregations were observed only in July, and an aggregation of a single male and two or more females was common in October and November. Aggregations were uncommon at Terrigal Haven, with significantly more females $(88.0 \% ; G=32.62, \mathrm{df}=1, P<.001)$ 
TABLE 3

Mean and $t$-Test Results for Separation Distances between All Individuals in Female, Male, and Male-Female Aggregations of Resting Adult H. portusjacksoni at Cabbage Tree Harbour and Dent Rock and Juveniles at Murray's Sandline

\begin{tabular}{|c|c|c|c|c|c|c|}
\hline \multirow[b]{2}{*}{ Site } & \multirow[b]{2}{*}{ Pair } & \multicolumn{3}{|c|}{ Separation Distance $(\mathrm{m})$} & \multirow[b]{2}{*}{ Comparison } & \multirow[b]{2}{*}{$t$} \\
\hline & & Mean & SE & Total Individuals & & \\
\hline \multirow[t]{2}{*}{ Cabbage Tree Harbour } & $\mathrm{F}: \mathrm{M}$ & 1.10 & 0.49 & 3 & \multirow[t]{2}{*}{$F: F \vee F: M$} & \multirow[t]{2}{*}{$0.72^{\mathrm{ns}}$} \\
\hline & $\mathrm{F}: \mathrm{F}$ & 1.51 & 0.27 & 33 & & \\
\hline \multirow{3}{*}{ Dent Rock } & $M: M$ & 0.66 & 0.07 & 68 & $M: M$ v F:M & $-2.48^{*}$ \\
\hline & $\mathrm{F}: \mathrm{M}$ & 0.98 & 0.11 & 42 & $M: M$ v F:F & $-0.80^{\mathrm{ns}}$ \\
\hline & $\mathrm{F}: \mathrm{F}$ & 0.74 & 0.08 & 78 & $F: F$ v F:M & $-1.69^{\mathrm{ns}}$ \\
\hline \multirow[t]{3}{*}{ Murray's Sandline } & M:M & 0.53 & 0.17 & 4 & $M: M$ v F:M & $1.50^{\mathrm{ns}}$ \\
\hline & $\mathrm{F}: \mathrm{M}$ & 0.30 & 0.10 & 16 & $M: M \vee F: F$ & $0.77^{\mathrm{ns}}$ \\
\hline & $\mathrm{F}: \mathrm{F}$ & 0.37 & 0.10 & 12 & $F: F$ $F: M$ & $0.98^{\mathrm{ns}}$ \\
\hline
\end{tabular}

${ }^{*}, P<.05 ;{ }^{\text {ns }}, P>.05$.

and males $(80.6 \% ; G=14.44, \mathrm{df}=1, P<$ .001) being solitary than in aggregations. Of the four mixed-sex aggregations at Terrigal Haven, two involved sharks actively mating. The largest single-sex aggregation consisted of three males, with the remaining four aggregations consisting of only two individuals.

At Cabbage Tree Harbour and Dent Rock there was no significant difference in the mean distance between individuals in femaleonly and mixed-sex aggregations (Table 3). However, at Dent Rock there was a significant difference in the mean separation distance of individuals in male-only and mixed-sex aggregations, with individuals in the male-only aggregation being closer together (Table 3, Figure 3). At Dent Rock there was no significant difference in the mean separation distance between individuals in male-only and female-only aggregations.

At Murray's Sandline $82.7 \%$ of juvenile females and males were solitary. The majority of aggregations $(86.7 \%)$ involved only two individuals, and four aggregations (13.3\%) consisted of three individuals. There was no significant difference between the number of male-only and female-only aggregations $(G=$ 1.97 , $\mathrm{df}=1, P=.16$ ) or between single-sex and mixed-sex aggregations $(G=0, \mathrm{df}=1$, $P=1$ ). Two additional aggregations included unsexed individuals with female juveniles and two with male juveniles. There were no sig- nificant differences in the mean separation distances between juvenile individuals in male-only, female-only, or mixed-sex aggregations at Murray's Sandline (Table 3, Figure 3).

\section{Spatial Movements and Activity Spaces}

A $290 \mathrm{~mm}$ TL male juvenile (N353) was monitored for a total of $25 \mathrm{hr}$ and $50 \mathrm{~min}$, after which it could not be relocated. The activity space of $\mathrm{N} 353$ ranged from $3,510 \mathrm{~m}^{2}$ (50\% fixed kernel) to $40,870 \mathrm{~m}^{2}$ (95\% fixed kernel) centered over the sand/sea-grass interface (Figure 4). The minimum convex polygon area for $\mathrm{N} 353$ was $63,520 \mathrm{~m}^{2}$. However, this individual could not be located from 1900 hours to 0650 hours on day 1 and is believed to have moved a considerable distance from Murray's Sandline. A $295 \mathrm{~mm}$ TL male juvenile (N354) was monitored for a total of $32 \mathrm{hr}$ and $20 \mathrm{~min}$, after which it could not be relocated. The activity space of N354 ranged from $40,920 \mathrm{~m}^{2}$ (50\% fixed kernel) to $583,990 \mathrm{~m}^{2}$ (95\% fixed kernel) spread broadly across the sea-grass nursery area (Figure 4). The minimum convex polygon area for N354 was $623,520 \mathrm{~m}^{2}$. This individual was not located from 0140 hours to 0410 hours on day 1 and was lost permanently after 2140 hours on day 2. On the latter occasion the juvenile was moving away from Murray's 

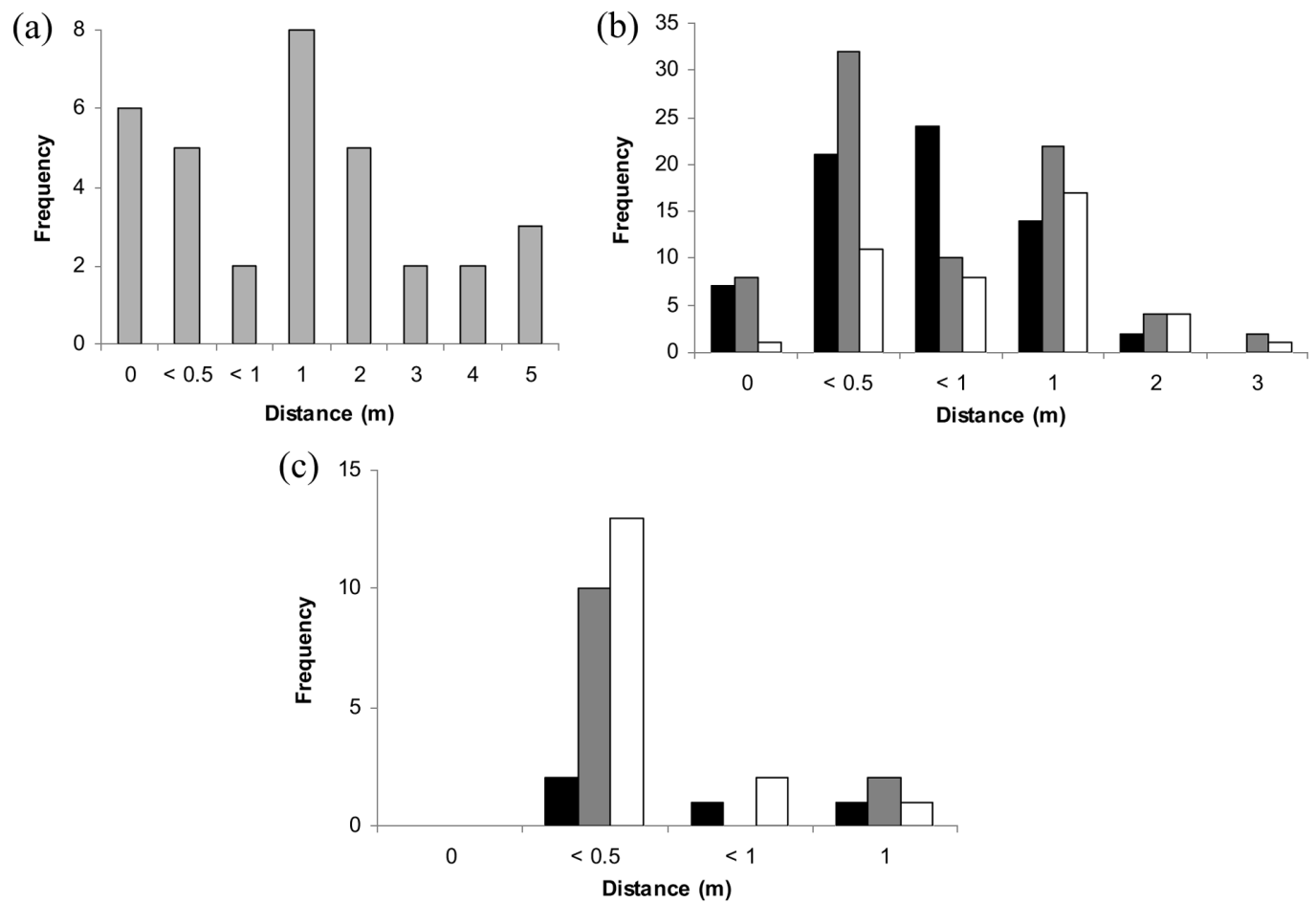

Figure 3. Distance (in meters) between all individuals in female-only (gray bars), male-only (black bars), and malefemale (white bars) aggregations for resting adult H. portusjacksoni at (a) Cabbage Tree Harbour and (b) Dent Rock and juveniles at (c) Murray's Sandline.

Sandline in a northeasterly direction toward the entrance of Jervis Bay. Both individuals were briefly relocated 28 days after tagging near the northern side of Bowen Island ( $\sim 2.5 \mathrm{~km}$ from their tagging position) but could not be tracked due to sea conditions.

Juvenile N353 was recorded for eight periods of inactivity ranging from 10 to $130 \mathrm{~min}$ $(71.3 \pm 15.6$ min [mean \pm SE] $)$ and five periods of movement ranging from 10 to $20 \mathrm{~min}$ $(12.0 \pm 4.5 \mathrm{~min})$ during daylight hours. Only one $60 \mathrm{~min}$ period of inactivity was recorded during the night, after which this shark was not detected on the track until the following morning. There was no significant difference in the number of inactive and mobile periods $(G=0.70, \mathrm{df}=1, P=.40)$; however significantly more time on average was spent inactive than mobile $(G=46.80, \mathrm{df}=1, P<$ $.001)$. Juvenile N354 was recorded for 11 periods of inactivity ranging from 10 to $150 \mathrm{~min}$
$(58.2 \pm 14.9 \mathrm{~min})$ and nine periods of movement ranging from 10 to $20 \mathrm{~min}(11.1 \pm 1.1$ min) during daylight hours. At night, 10 periods of inactivity ranging from 10 to $110 \mathrm{~min}$ $(39.0 \pm 10.9 \mathrm{~min})$ and seven periods of movement ranging from 10 to $90 \mathrm{~min}(32.9 \pm 13.6$ $\mathrm{min}$ ) were recorded. There was no significant difference in the number of inactive and mobile periods during the day $(G=0.20, \mathrm{df}=1$, $P=.65)$ or night $(G=0.53, \mathrm{df}=1, P=.47)$ or in the average time of movement and inactivity at night $(G=0.52, \mathrm{df}=1, P=.47)$. However, there was significantly more inactive time on average during the day $(G=$ $35.09, \mathrm{df}=1, P<.001)$.

Rate of movement could be calculated only for juvenile N354 and related to three periods of straight-line swimming for three or more consecutive fixes ( $n=14$ intervals). The distance covered during these movements ranged from 86 to $176 \mathrm{~m}$ (113.8 \pm 

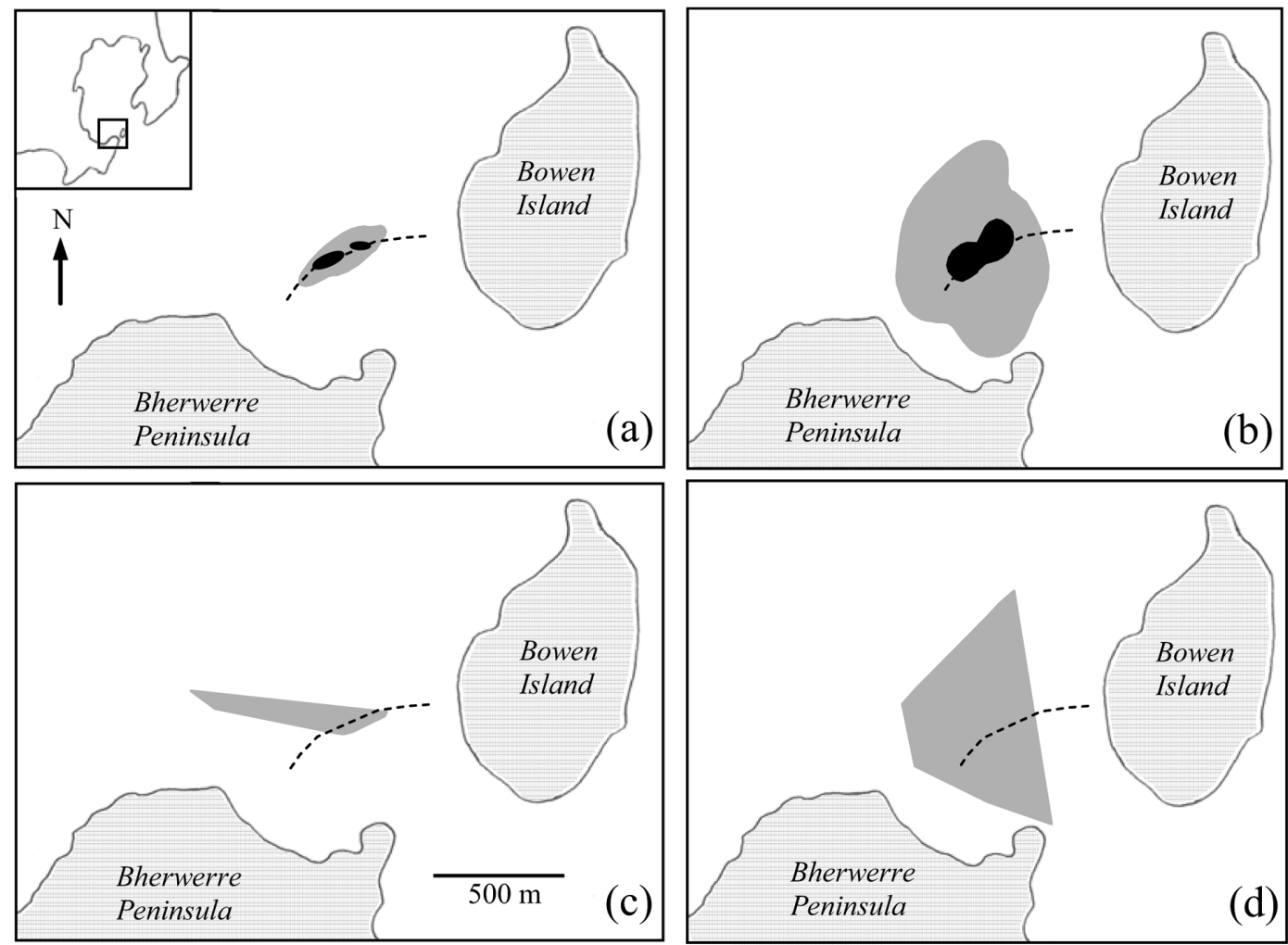

FIgURE 4. Activity spaces of $(a, c) 290 \mathrm{~mm}$ TL male (N353) and $(b, d) 295 \mathrm{~mm}$ TL male (N354) H. portusjacksoni at Murray's Sandline. $(a, b)$ show fixed kernel activity spaces: $50 \%$ (black shading) and $95 \%$ (gray shading); $(c, d)$ show minimum convex polygon ranges (gray shading). Inset shows the area of Jervis Bay depicted in the main maps. Dashed line indicates sand/sea-grass interface of Murray's Sandline.

$7.97 \mathrm{~m})$ per $10 \mathrm{~min}$ interval. The rate of movement ranged from 0.1 to $0.3 \mathrm{~m} \mathrm{sec}^{-1}$ $\left(0.19 \pm 0.01 \mathrm{~m} \mathrm{sec}^{-1}\right)$. An adult male and adult female monitored for $27 \mathrm{hr}$ did not move from their tagging site. Accordingly an activity space could not be calculated.

\section{DISCUSSION}

\section{Site Fidelity}

Adult and juvenile $H$. portusjacksoni of both sexes exhibited strong site fidelity, with the vast majority of resightings at the original tagging site up to three seasons after tagging. This indicates that adult $H$. portusjacksoni have a strong philopatric tendency for specific breeding reefs. Although the possibility exists that tagged sharks utilized reefs not surveyed in the current study, this is considered unlikely. Information on the tagging program was distributed to dive operators and clubs servicing the regions where tagging occurred, and the tags were clearly marked with contact details. Despite this, no such reports were received.

The strength of male philopatry was equivalent to that of females. Although McLaughlin and O'Gower (1971) found evidence of site fidelity in adult $H$. portusjacksoni, this mainly involved individuals resighted within the same season they were tagged. Only a small number of females and one male were resighted after several seasons. On this basis, McLaughlin and O'Gower (1971) postulated that males may be less philopatric 
than females. However, in our study comparable numbers of males and females were resighted at the original tagging reef after multiple seasons. Females appeared to spend relatively more time on these reefs than males, which may relate to their requirement to oviposit at these sites. The exception to this pattern was Cabbage Tree Harbour, with none of the 35 tagged sharks resighted there. However, this site was not involved in reproductive activity (Powter 2006). This suggests that females may utilize resting habitat near reproductive sites but not exhibit long-term site fidelity at these locations. Site fidelity related to reproductive activity is known in several elasmobranch species. Female lemon sharks, Negaprion brevirostris, show strong parturition-related philopatry to Bimini Lagoon, which they may use as an exclusive reproductive site (Feldheim et al. 2002, Edren and Gruber 2005). Female blacknose sharks, Carcharbinus acronotus, exhibit nursery area philopatry in the Gulf of Mexico area (Keeney et al. 2003).

The cause of philopatric behavior in elasmobranchs remains unclear; however it may relate to the reuse of quality habitat for mating, feeding, or parturition (Hueter et al. 2004). Nonetheless, site fidelity and philopatry have important implications for an understanding of stock structures, genetic diversity, fishery management, and conservation (Hueter et al. 2004). For example, philopatry may restrict gene flow and result in genetic divergence between populations that otherwise appear to have high dispersal potential (Keeney et al. 2003). This is likely to be important for $H$. portusjacksoni because the strong philopatric tendency demonstrated by both males and females within and between seasons suggests that discrete breeding populations exist, with little interchange between them despite the extensive migrations they undertake (Powter 2006). In addition, management of $H$. portusjacksoni from a fishery perspective must recognize these population-level differences and the impacts likely at local levels should a fishery develop.

Juvenile $H$. portusjacksoni also exhibited strong site fidelity within the sea-grass nursery, with resightings occurring up to 26 months after tagging. Hence, this sea-grass bed represents an important habitat for juvenile $H$. portusjacksoni. However, there is differential use of sections of the site, suggesting that some areas have greater importance than others. The eastern region of the sea-grass bed was used by significantly more juveniles than the western region and appeared to be the core area of the nursery site. This may relate to the more steeply sloped aspect of the sea-grass bed in that area, which possibly acts as a flow refuge sheltering resting juveniles from strong water movements (Powter 2006). Neonate blacktip sharks, Carcharbinus limbatus, also occupied a core area within their nursery area in Terra Ceia Bay, which was possibly a refuge from predators and from which feeding forays were made (Heupel et al. 2004).

\section{Spatial Distribution and Aggregations}

Noting the presence of clustered groups of adult $H$. portusjacksoni, McLaughlin (1969) suggested that social aggregation may be an important characteristic of the species. Although aggregations of individuals were observed in our study, they were not a dominant feature of the spatial distribution of H. portusjacksoni. At Dent Rock and Terrigal Haven adults were equally likely to be in aggregations as they were to be solitary. Only at Cabbage Tree Harbour were significantly more individuals in aggregations, and this appeared to be related to the different physical environment (e.g., presence of gutters) that promoted aggregative behavior by concentrating individuals into a restricted area of favored habitat (Powter 2006). A number of shark species are known to aggregate for a variety of reasons, but social behavior is not the only factor. Captive bull huss, Scyliorhinus stellaris, forms resting groups with fluid membership that may be socially mediated (Scott et al. 1997). Female gray reef sharks, Carcharbinus amblyrbyncos, aggregate daily at their breeding reefs (Economakis and Lobel 1998), and whale sharks, Rbincodon typus, aggregate to take advantage of transient food resources (Heyman et al. 2001). The main factor generating aggregations in adult $H$. 
portusjacksoni appears to be habitat variation. Resting individuals at Cabbage Tree Harbour were found almost exclusively within the site's narrow rock gutters, which limit the available area for sharks to disperse. Terrigal Haven, where aggregations are rare, has no rock gutters, and resting sharks predominantly occurred at the interface between the rocky reef and the sand seafloor. Dent Rock has a number of broad gutters, which often contain aggregations of $H$. portusjacksoni, but individuals were also dispersed around the reef interface. However, resting individuals using the interface at Terrigal Haven and Dent Rock were on the lee side of the reef, unlike Cabbage Tree Harbour where the interface was exposed to the prevailing seas (Powter 2006). Hence resting individuals were infrequently found at the exposed interface at Cabbage Tree Harbour.

Reproductive activities may also influence the composition of aggregations. Male-only aggregations were observed in July when females were generally absent. However, aggregations involving a single male and several females were more commonly observed later in the season. Although there was no difference in the mean spacing of individuals in male-only or female-only aggregations, males in male-only aggregations were closer together than individuals in mixed-sex aggregations. This was largely due to mixed-sex aggregations predominantly consisting of a group of females with a single male slightly offset from the group. This male positioning may relate to "guarding" females; however no territorial interactions between individuals were observed. McLaughlin (1969) considered similar separation of males and females as possible evidence of sexual segregation. However, this was not supported by our study, with male and female $H$. portusjacksoni found on the same reefs at the same time and in mixed aggregations. It is more likely that the spatial separation observed by McLaughlin (1969) was related to the reproductive behavior mentioned earlier.

Juvenile $H$. portusjacksoni were far more likely to occur as solitary individuals, with the small number of aggregations observed consisting of two or three individuals. Hence, aggregations by juveniles appeared to be chance events, with no significant differences in the numbers of single- or mixed-sex aggregations or in the mean separation of aggregating individuals. The low number of juvenile aggregations within the sea-grass bed is consistent with the hypothesis of habitat-mediated aggregations for adults, because the sea-grass bed itself contains no features to produce aggregations. However, other factors, such as the avoidance of food competition, may also be involved, with juveniles observed feeding in the sea-grass bed on several occasions (pers. obs.). Fine-scale examination of juvenile aggregations has not previously been investigated for elasmobranchs. Heupel and Simpfendorfer (2005) utilized arrays of automated acoustic monitors to demonstrate that juvenile blacktip sharks, Carcharbinus limbatus, aggregate within their nursery area; however nearest neighbor distances ranged from $500 \mathrm{~m}$ to $1.8 \mathrm{~km}$.

\section{Activity Space and Spatial Movements}

The two acoustically monitored adults in this study remained inactive in the same site for at least $27 \mathrm{hr}$. McLaughlin (1969) found that locomotory activity in captive adult $H$. portusjacksoni averaged $2 \mathrm{hr}$ per day, with short bouts of continuous swimming generally lasting less than $1 \mathrm{~min}$. However, this may have been due to the pool environment in which they were housed, which measured only 30 by 13 by $2.6 \mathrm{~m}$ and held six adult $H$. portusjacksoni. Acoustic studies of free-ranging individuals were largely unsuccessful but did show lengthy periods of inactivity (McLaughlin 1969).

Acoustic tracks of two juvenile males revealed different behavior and use of space. Long periods of inactivity were common; however one (N354) moved more often and over larger distances. Similarly, there was significant variation in the size of their activity spaces, although both were centered over core areas of the sea-grass bed. Significantly, both individuals were unable to be detected for lengthy periods of time, mainly at night, and extensive searches of the surrounding bay up to $5 \mathrm{~km}$ from the tagging site failed 
to detect either individual. N353 was relocated after an extensive absence approaching the sea-grass bed from the northwest, and N354 was tracked on a different occasion moving off to the northeast toward the mouth of Jervis Bay. This suggests that the area utilized by the juveniles is significantly larger than the area determined through acoustic tracking. This broader area may extend farther into Jervis Bay (northwest) or possibly outside the bay (northeast), which is only 2 to $3 \mathrm{~km}$ from the sea-grass bed. Hence, the activity space of juvenile $H$. portusjacksoni could be several orders of magnitude higher than determined in this study and may possibly extend outside the protective waters of the marine protected areas in which the seagrass bed is located.

Broad variation in activity space size is known in juvenile elasmobranchs. Juvenile sandbar sharks, Carcharbinus plumbeus, (57$132 \mathrm{~cm} \mathrm{TL}$ ) in Delaware Bay had activity spaces ranging from 1.0 to $355.1 \mathrm{~km}^{2}$ (Rechisky and Wetherbee 2003), and that of juvenile lemon sharks, Negaprion brevirostris, (46.8-100.6 cm precaudal length) ranged between 0.23 and $1.26 \mathrm{~km}^{2}$ (Morrissey and Gruber 1993). Daily home ranges of juvenile blacktip sharks, Carcharbinus limbatus, ranged from $19 \mathrm{~m}^{2}$ to $13.0 \mathrm{~km}^{2}$ (Heupel et al. 2004). Although the activity space utilized by juvenile $H$. portusjacksoni was generally smaller than that of those juvenile elasmobranchs, the individuals studied were considerably larger than the juvenile $H$. portusjacksoni in this study and were not demersal species. Kramer and Chapman (1999) found a positive relationship between home range size and body size in 29 species of coral reef fish, and the activity spaces in our study were comparable with, or larger than, those found by Kramer and Chapman (1999) on the basis of body size. Despite the variation in home range size, studies of juvenile shark movement patterns show high levels of site fidelity, restricted activity spaces, and repetitive movement regimes (Heupel et al. 2004). Although the activity space of juvenile $C$. plumbeus studied in Delaware Bay varied considerably, individuals spent up to $90 \%$ of their time within a core area (Rechisky and Wetherbee
2003). Similarly, neonate blacktip sharks, Carcharbinus limbatus, were found to occupy a restricted portion of their nursery area (Heupel et al. 2004). The movement analysis of juvenile $H$. portusjacksoni coupled with the site fidelity exhibited for the sea-grass bed at Murray's Sandline indicates that it was an important core habitat area for them. However, the current study does not allow conclusions to be drawn about the duration of use of the identified activity space, and longer-term studies would provide more rigorous data concerning the importance of this habitat.

Rate of movement estimates for one juvenile male $(\mathrm{N} 354)$ ranged from 0.14 to $0.29 \mathrm{~m}$ $\mathrm{sec}^{-1}$, or $0.50-1.04 \mathrm{~km} \mathrm{hr}^{-1}$. This rate is consistent with rate of movement values for other demersal elasmobranchs, such as $0.64 \mathrm{~km}$ $\mathrm{hr}^{-1}$ for the Hawaiian stingray, Dasyatis lata (Cartamil et al. 2003), and $0.49 \mathrm{~km} \mathrm{hr}^{-1}$ for the leopard shark, Triakis semifasciata (Ackerman et al. 2000). It is also consistent with known rates of other juvenile elasmobranchs, including $0.64 \mathrm{~km} \mathrm{hr}^{-1}$ for juvenile scalloped hammerheads, Sphyrna lewini (Holland et al. 1993), and $1.51 \mathrm{~km} \mathrm{hr}^{-1}$ for juvenile sandbar sharks, Carcharbinus plumbeus (Rechisky and Wetherbee 2003). Although not moving at a rapid pace, juvenile $H$. portusjacksoni demonstrated an ability to maintain this rate of movement for a sustained period. On one occasion a $295 \mathrm{~mm}$ TL juvenile swam at an average rate of movement of $0.16 \mathrm{~m} \mathrm{sec}^{-1}$ for 70 min. Despite its small body size this individual clearly demonstrated an ability to cover moderate distances without breaks or indications of a decrease in speed.

\section{CONCLUSIONS}

The spatial ecology of $H$. portusjacksoni is strongly habitat-mediated. Exhibiting ties to specific breeding reefs, adult $H$. portusjacksoni displayed strong site fidelity over periods of at least 4 yr. Juveniles showed a strong link to their sea-grass nursery habitat, exhibiting site fidelity for periods in excess of $2 \mathrm{yr}$ and utilizing moderately sized activity spaces centered over a core area of that sea-grass bed. Similarly, aggregatory behavior was predominantly habitat-mediated rather than socially 
driven as previously suggested. Favored habitat types with restricted size, such as gutters, were the prime factor generating aggregations. Representing the first quantitative study of the spatial ecology of wild populations of $H$. portusjacksoni, this study indicates the importance of habitat conservation to this species.

\section{ACKNOWLEDGMENTS}

All work was conducted under University of Newcastle Ethics Approval 804, NSW Fisheries Scientific Collection Permit P02/0042, and Environment Australian Research Activity Permit BDR02/00015 and renewals.

\section{Literature Cited}

Ackerman, J. T., M. C. Kondratieff, S. A. Matern, and J. J. Cech Jr. 2000. Tidal influences on spatial dynamics of leopard sharks, Triakis semifasciata, in Tomales Bay, California. Environ. Biol. Fish. 58:33-43.

Begon, M., J. L. Harper, and C. R. Townsend. 1990. Ecology: Individuals, populations and communities. Blackwell Scientific, Cambridge, Massachusetts.

Cartamil, D. P., J. J. Vaudo, C. G. Lowe, B. M. Wetherbee, and K. N. Holland. 2003. Diel movement patterns of the Hawaiian stingray, Dasyatis lata: Implications for ecological interactions between sympatric elasmobranch species. Mar. Biol. (Berl.) 142:841-847.

Economakis, A. E., and P. S. Lobel. 1998. Aggregation behavior of the grey reef shark, Carcharbinus amblyrbynchos, at Johnston Atoll, central Pacific Ocean. Environ. Biol. Fish. 51:129-139.

Edren, S. M. C., and S. H. Gruber. 2005. Homing ability of young lemon sharks, Negaprion brevirostris. Environ. Biol. Fish. 72:267-281.

Feldheim, K. A., S. H. Gruber, and M. V. Ashley. 2002. The breeding biology of lemon sharks at a tropical nursery lagoon. Proc. R. Soc. Lond. B Biol. Sci. 269:16551661.
Heithaus, M. R. 2001. The biology of tiger sharks, Galeocerdo cuvier, in Shark Bay, Western Australia: Sex ratio, size distribution, diet, and seasonal changes in catch rates. Environ. Biol. Fish. 61:25-36.

Heupel, M. R., and C. A. Simpfendorfer. 2005. Quantitative analysis of aggregation behavior in juvenile blacktip sharks. Mar. Biol. (Berl.) doi:10.1007/s00227-0050004-7.

Heupel, M. R., C. A. Simpfendorfer, A. B. Collins, and J. P. Tyminski. 2006. Residency and movement patterns of bonnethead sharks, Sphyrna tiburo, in a large Florida estuary. Environ. Biol. Fish. 76:47-67.

Heupel, M. R., C. A. Simpfendorfer, and R. E. Hueter. 2004. Estimation of shark home ranges using passive monitoring techniques. Environ. Biol. Fish. 71:135142.

Heyman, W. D., R. T. Graham, B. Kjerfve, and R. E. Johannes. 2001. Whale sharks Rhincodon typus aggregate to feed on fish spawn in Belize. Mar. Ecol. Prog. Ser. 215:275-282.

Holland, K. N., C. G. Lowe, J. D. Peterson, and A. Gill. 1992. Tracking coastal sharks with small boats: Hammerhead shark pups as a case study. Aust. J. Mar. Freshwater Res. 43:61-66.

Holland, K. N., B. M. Wetherbee, J. D. Petersen, and C. G. Lowe. 1993. Movements and distribution of hammerhead shark pups on their natal grounds. Copeia 1993 (2): 495-502.

Hueter, R. E. 1998. Philopatry, natal homing and localised stock depletion in sharks. Shark News. Newsletter of the IUCN Shark Specialist Group 12:5.

Hueter, R. E., M. R. Heupel, E. J. Heist, and D. B. Keeney. 2004. Evidence of philopatry in sharks and implications for the management of shark fisheries. J. Northwest Atl. Fish. Sci. 35:239-247.

Keeney, D. B., M. Heupel, R. E. Hueter, and E. J. Heist. 2003. Genetic heterogeneity among blacktip shark, Carcharbinus limbatus, continental nurseries along the U.S. Atlantic and Gulf of Mexico. Mar. Biol. (Berl.) 143:1039-1046. 
Klimley, A. P., B. J. Le Boeuf, K. M. Cantara, J. E. Richert, S. F. Davis, and S. van Sommeran. 2001. Radio-acoustic positioning as a tool for studying site-specific behavior of the white shark and other large marine species. Mar. Biol. (Berl.) 138:429-446.

Kramer, D. L., and M. R. Chapman. 1999. Implications of fish home range size and relocation for marine reserve function. Environ. Biol. Fish. 55:65-79.

McLaughlin, R. H. 1969. The ecology of heterodont sharks. Ph.D. diss., University of New South Wales, Sydney, Australia.

McLaughlin, R. H., and A. K. O'Gower. 1971. Life history and underwater studies of a heterodont shark. Ecol. Monogr. 41:271-289.

Morrissey, J. F., and S. H. Gruber. 1993. Home range of juvenile lemon sharks, Negaprion brevirostris. Copeia 1993 (2): 425-434.

Powter, D. M. 2006. Conservation biology of the Port Jackson shark, Heterodontus portusjacksoni, in New South Wales. Ph.D. diss., University of Newcastle, Ourimbah, New South Wales, Australia.

Rechisky, E. L., and B. M. Wetherbee. 2003. Short-term movements of juvenile and neonate sandbar sharks, Carcharbinus plumbeus, on their nursery grounds in Delaware Bay. Environ. Biol. Fish. 68:113128.
Rodgers, A. R., and A. P. Carr. 1998. HRE: The Home Range Extension for ArcView. Ontario Ministry of Natural Resources, Centre for Northern Forest Ecosystem Research, Thunder Bay, Ontario, Canada. Scott, G. W., K. Gibbs, and J. Holding. 1997. Group 'resting' behaviour in a population of captive bull huss (Scyliorbinus stellaris). Aquarium Sci. Conserv. 1:251-254.

Seaman, D. E., and R. A. Powell. 1996. An evaluation of the accuracy of kernel density estimators for home range analysis. Ecology 77:2075-2085.

Simpfendorfer, C. A., and M. R. Heupel. 2004. Assessing habitat use and movement. Pages 553-572 in J. C. Carrier, J. A. Musick, and M. R. Heithaus, eds. Biology of sharks and their relatives. CRC Press, Boca Raton, Florida.

Sokal, R. R., and F. J. Rohlf. 1995. Biometry: The principles and practice of statistics in biological research. W. H. Freeman, New York.

Sundstrom, L. F., S. H. Gruber, S. M. Clermont, J. P. S. Correia, J. R. C. de Marignac, J. F. Morrissey, C. R. Lowrance, L. Thomassen, and M. T. Oliveira. 2001. Review of elasmobranch behavioral studies using ultrasonic telemetry with special reference to the lemon shark, Negaprion brevirostris, around Bimini Islands, Bahamas. Environ. Biol. Fish. 60:225-250. 